\title{
A crise da Masculinidade: Uma Crítica à Identidade de \\ Gênero e à Literatura Masculinista $^{1}$
}

The male crisis:

A gender identity and male literature criticism

Sergio

Gomes da Silva

Instituto de

Medicina Social/

IMS/Universidade

do Estado do Rio de

Janeiro
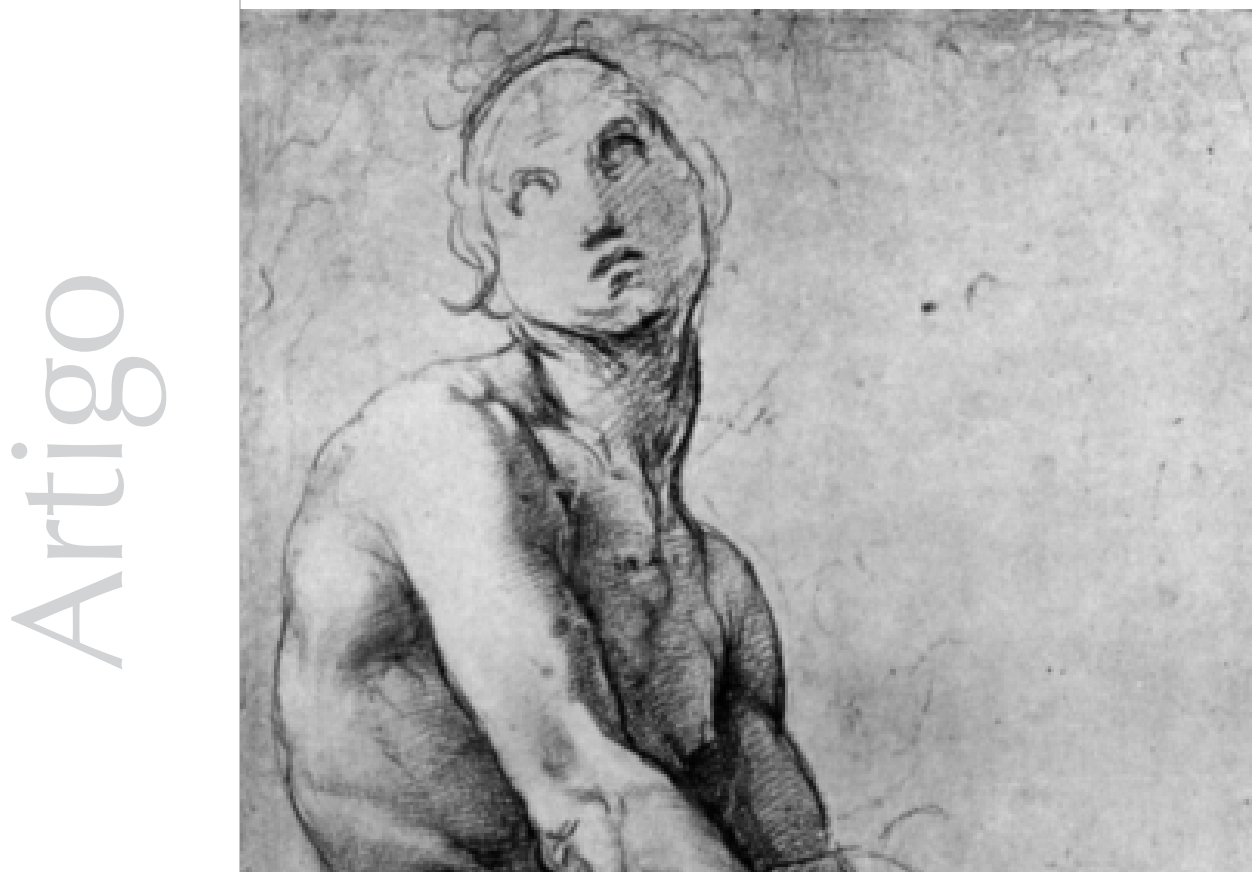

1 Este artigo é resultante de meu trabalho de Pós. Graduação Lato Sensu, Especialização em Sexualidade Humana, realizado pelo Centro de Educação na Universidade Federal da Paraíba, campus I, efoi a base de uma apresentação, sob o mesmo título, na mesa redonda "Sexualidade relaçöes afetivas e malestar", no III Congresso Mal-Estar e Subjetividade, 10 a 12 de maio de 2000, UNIFOR Universidade de Fortaleza, Fortaleza-Ce. A presente versão é inédita e sofreu algumas modificações e revisão da literatura para a sua publicação. 


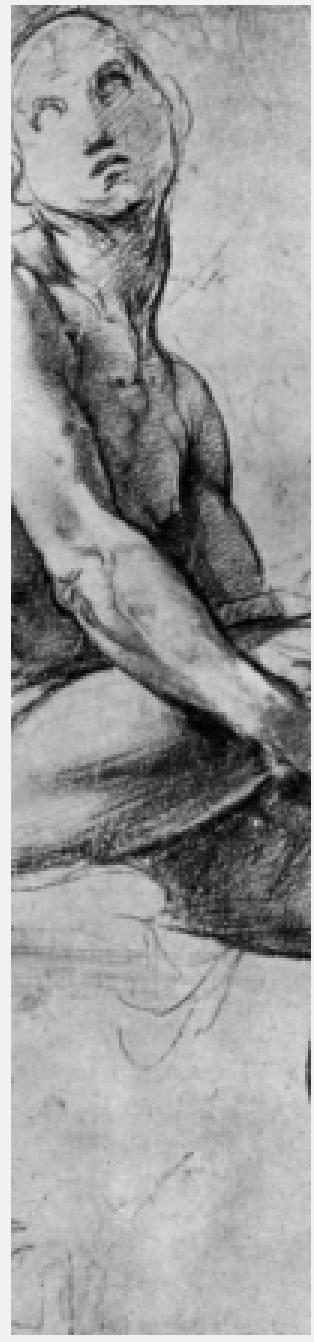

Resumo: Nos últimos anos, tem se discutido acerca da atual crise da masculinidade. O "novo homem" estaria em crise porque não encontraria modelos identitários hegemônicos para descrever sua nova condição masculina. Os reflexos dessa crise se devem à maior participação das mulheres no campo do trabalho, do avanço da tecnologia no campo da sexualidade, na pluralidade de papéis e identidades sexuais, na redefinição do papel de pai, na maior preocupação com o corpo e com a estética e a tentativa de manter e sustentar um modelo hegemônico único no papel masculino. A partir disto, o presente trabalho objetiva analisar a atual crise da masculinidade, a partir de uma crítica do conceito de identidade de gênero e da literatura masculinista enquanto representantes dos men's studies. Propõe-se, como saída mais ética, a definição do sujeito de acordo com o neopragmatismo lingüístico.

Palavras-chave: crise da masculinidade, identidade de gênero e sexual, neopragmatismo.

Abstract: In the last years it was observed an increasing discussion in the crisis of masculinity. The "new man" would be in crisis because he isn't able to find out an hegemonic identity model to describe his new condition. This crisis is reflected in the entry of women in the work field, high technology of reproduction and sexuality, uncountable roles and cares about body and aesthetic beauty and the attempt to keep a hegemonic and traditional model of man. From this point of view, this study tries to analyse the crisis of masculinity through a criticism of gender identity and male literature as a result of men's studies. We propose, as an ethical approach, the definition of subject according to neopragmatism theory.

Key words: male crisis, gender and sexual identity, neopragmatism.

\section{Há uma crise da masculinidade hoje, e se há, como podemos descrevê-la?}

Para alguns autores (Badinter, 1993; Nolasco, 1995a, 1995b; Almeida, 1996; Dorais, 1994a, 1994b; Almeida, 1995 e Ceccarelli, 1997), a crise da masculinidade contemporânea foi um reflexo do movimento feminista ocorrido no final da década de 60, e levou alguns homens a buscarem um modelo que melhor conseguisse descrever suas subjetividades.

A partir de então, passou-se a observar alguns sinais dessa crise, como a criação de clubes de recuperação da masculinidade (bem mais próximo do modelo tradicional) e grupos de discussão e de psicoterapia constituídos exclusivamente por homens, em busca de um novo modelo de masculinidade.

Outro sinal dessa crise estaria na compreensão de uma "feminilização do masculino", na maior visibilidade da homo e bissexualidade entre os homens, assim como drag-queens, travestis e transexuais conformariam figuras possíveis na constituição das subjetividades masculinas. 
A cultura e as sociedades ocidentais de massa

condicionaram, em parte, a descrição do sujeito através de modelos normativos (de gênero e sexual), sem importar-se com as construções singulares do próprio sujeito.
Um resultado disso foi a conseqüente criação dos estudos masculinistas, ou men's studies, inicialmente em países mais desenvolvidos, como é o caso dos Estados Unidos, França e Inglaterra, e o aumento de uma produção literária, a qual denominamos literatura masculinista, que tentam propor soluções para esse mal-estar do homem contemporâneo.

Entendemos por literatura masculinista a produção literária dos men's studies, ou seja, aquela que desconstruiu uma identidade masculina baseada nos idéias de masculinidade oitocentista, tradicional, e que viu na pluralidade do gênero uma espécie de "feminilização" do masculino. A literatura masculinista ressalta, querendo ou não, uma espécie de essência identitária comum a todos os homens, não só biológica como também sexual e comportamental, criticando o modelo tradicional de masculinidade e admitindo, como verdade única, a essência pluralista dos gêneros.

Não obstante, o sentido que damos para o mal-estar é semelhante àquele referido por Freud (1930[1929]), na forma conferida por Figueiredo (1998b), ou seja, "um estado crônico mas tolerável de desprazer, intrínseco à constituição do psiquismo e uma condição básica para a procura, pelo homem, das felicidades possíveis" (p. 01). O estado de desprazer, de insatisfação psíquica, é o que guiará, no nosso entendimento, a atual crise da masculinidade. Fala-se, e muito, do verdadeiro significado do que é ser homem na contemporaneidade, talvez como resultado de sua inserção na cultura à qual pertence, onde, por conseguinte, precisa moldar-se sustentando ou criticando, aderindo ou rejeitando, integrando-se ou afastando-se, obedecendo ou resistindo às regras impostas pela cultura e definidas como normas, conformando características, comportamentos e papéis que não necessariamente sejam aqueles que condizem com aquilo que ele almeja para si enquanto traços identificatórios. A cultura é, portanto, "o expediente que a natureza (humana) inventa para defender-se de suas deficiências e de seus excessos. $\mathrm{Na}$ "cultura", Freud, como se sabe, inclui os instrumentos e as técnicas para o domínio das forças naturais, os regulamentos - interdições e prescrições - ordenadores das relações entre os homens, os modelos e os ideais capazes de organizar e estabilizar a vida coletiva e ainda as ilusões necessárias à conservação da própria cultura", ou seja, "a cultura é necessária para proteger a natureza de si mesma - em estado natural, a natureza humana seria inviável; mas atenção: a cultura tem efeitos colaterais indesejados" (Figueiredo, 1998b, p. 02).

Compreenderemos cultura, também, conforme a definição de Tylor e Levi Strauss, citado por Franchetto, Cavalcanti e Heilborn (1980), a saber, "um todo complexo que inclui conhecimento, crença, arte, leis, moral, costumes e quaisquer outras capacidades e hábitos adquiridos pelo homem enquanto membro da sociedade" (p. 17), ou, dito de outra forma, "vista como um sistema, como um conjunto de regras/redes de significação, é a cultura que dá sentido, simultaneamente, ao mundo social e natural. Comportamentos, instituições e valores de um grupo social só ganham sentido no interior do sistema cultural como um todo" (p.18).

A cultura e as sociedades ocidentais de massa condicionaram, em parte, a descrição do sujeito através de modelos normativos (de gênero e sexual), sem importar-se com as construções singulares do próprio sujeito.

Face a essas considerações, objetivamos analisar, neste trabalho, a atual crise da masculinidade, compreendendo-a como um mal-estar, um conflito identitário originado a partir do movimento feminista e que encontra ecos não só na primeira crise como também no culto à masculinidade ocorrido no século XIX, conforme apontam os trabalhos de Peter Gay (1995), Ceccareli (1997) e Badinter (1993). A partir do referencial teórico do conceito de 
singularidade ou processos de singularização formulado por Rolnick \& Guatari (1981) e Figueiredo (1998a, 1998b), somado a uma aproximação teórica do neopragmatismo lingüístico na forma conferida por Costa (1992, 1994, 1995a), Melo (1995), Ropa (1994) e Bezerra Júnior (1994), procedemos a uma análise e crítica do conceito de identidade de gênero e sexual, a partir do que Stoller (1993) denominou "núcleo de identidade de gênero", assim como da literatura masculinista, tomando como base a produção literária representada principalmente pelos trabalhos de Hite (1982), Falconet \& Lefaucher (1977), Dorais (1994a, 1994b), Almeida (1995), Veloso (1996), Nolasco (1993, 1995a, 1995b), Almeida (1996) e Arilha, Ridenti e Medrado (1998).

Ao proceder a essa revisão, fomos orientados não pela pergunta "o que é ser masculino ou feminino, homem ou mulher?", e sim, "como podem homens e mulheres se descreverem, na medida em que encontrem formas mais belas e harmônicas de viver?", aumentando, assim, seus acordos intersubjetivos.

\section{Sexo e gênero na constituição das identidades}

A crise da masculinidade contemporânea se configura a partir de um conflito identitário vivido pelo homem. No nosso entender, esse conflito se constitui a partir de dois momentos distintos: primeiro, a partir da tentativa de se manter um modelo de identidade de gênero hegemônico e, ao mesmo tempo, pluralista, ora baseado em modelos tradicionais ora em modelos modernos de masculinidade, e segundo, a partir da impossibilidade de sustentar essa hegemonia no que se refere às subjetividades da maioria dos homens.

O conceito de identidade hegemônica, que pode ser aplicado a diversos modelos identitários ora vigentes, pertence a Robert Connell, autor de "Maculinities", entre outros ensaios sobre masculinidades. Para o autor, a masculinidade hegemônica é uma "configuração de gênero que incorpora a resposta atual aceita para o problema da legitimidade do patriarcado, garantindo a posição dominante dos homens e a subordinação das mulheres. A hegemonia será estabelecida somente se existir correspondência entre o padrão cultural e o poder institucional, seja ele coletivo e/ou individual. Quando as condições para a defesa do patriarcado mudam, as bases para a dominação ou hegemonia de uma masculinidade particular são gradualmente destruídas. A hegemonia é vista como historicamente mutável" (Garcia, 1998, p. 46). Dito de outro modo, o conceito de masculinidade hegemônica está calcado nos modelos tradicionais e dos predicativos da personalidade do homem, qual seja, "machista, viril e heterossexual", do mesmo modo em que este deve apresentar distanciamento emocional, agressividade e comportamento de risco no seu dia a dia, ou seja, um homem bem mais próximo dos modelos do cavaleiro medieval, do guerreiro oitocentista e dos grandes soldados, ao passo que os novos modelos de masculinidade têm colocado em evidência uma preocupação quanto à redefinição do papel de pai, marido, amante, trabalhador e cidadão. Nesse sentido, as instituições nacionais e internacionais têm-se preocupado com essa pluralidade de modelos masculinos e colocado em sua agenda propostas de uma implementação de pesquisas e políticas públicas que venham minimizar os riscos que o "novo homem" pode vir a sofrer.

Ora, segundo Costa (1989), “a identidade é formulada por sistemas de representações diversas, e corresponde ao modo como o sujeito se atrela ao seu universo sociocultural. O conflito identitário se dá quando o processo ou desempenho identificatórios são atravancados por contradições internas a um sistema ou por incompatibilidade entre sistemas diversos, não conseguindo realizar as "...masculinidade hegemônica é uma "configuração de gênero que incorpora a resposta atual aceita para o problema da legitimidade do patriarcado, garantindo a posição dominante dos homens e a subordinação das mulheres."

Robert Connell 
exigências da norma identificatória e vindo o sujeito a sofrer psicologicamente, sendo sua identidade interpretada como desvio da normalidade" (p. 22).

A identidade de gênero e sexual são processos complexos, impostos ora por nossos pais e amigos, e cobrados direta ou indiretamente pela sociedade em que vivemos, conjurando a heterossexualidade como modelo normativo único e constitutivo das subjetividades da maioria dos homens.

Apesar de compreendermos a identidade sexual como sendo hetero, homo ou bissexual, nos dias atuais, entendemos também que há uma certa pluralidade de "tipos" sexuais, tais como o transexual, o travesti, e até mesmo o drag-queen e a drag-king figurariam como identidades sexuais possíveis. Por outro lado, entendemos identidade de gênero como o conjunto de traços construídos na esfera social e cultural por uma dada sociedade, que definem, em conseqüência, quais os gestos, os comportamentos, as atitudes, os modos de se vestir, falar e agir de forma semelhante para homens e mulheres. As identidades de gênero tendem a estar em consonância com o sexo biológico do sujeito, porém, não são estruturas fixas, encerradas em si mesmas; pelo contrário, podem e estão continuamente se renovando, em ebulição, e a cada momento podem ser novamente moldadas de outras formas. Elas também são impostas pelo processo de socialização, que impede construções singulares, moldando um "comportamento" comum a todos os indivíduos. Apesar de não ser uma condição para a formação das identidades sexuais, elas estão intimamente ligadas à escolha afetiva e sexual do sujeito. Nós podemos encontrar sujeitos masculinos ou femininos que não necessariamente pertencem ao seu sexo biológico e que podem fazer uma escolha afetiva e sexual do sexo oposto ao seu (Silva, 1999).
Quem não se enquadra nesses padrões, ou muda seus comportamentos, seus papéis sociais, seus desejos afetivos e sexuais, ou paga um alto preço em seu sofrimento psíquico. Por "papéis sociais" entendemos "padrões ou regras arbitrárias que uma sociedade estabelece para seus membros e que definem seus comportamentos, suas roupas, seus modos de se relacionar ou de se portar (...) através do aprendizado de papéis, cada um/a deveria conhecer o que é ser considerado adequado (e inadequado) para um homem ou para uma mulher numa determinada sociedade, e responder a essas expectativas" (Louro, 1997, p. 24).

\section{Mas como se constitui nossa identidade de gênero e sexual, enfim?}

Para Robert Stoller (1993), psicanalista e especialista em transexualidade, a masculinidade e a feminilidade são qualidades sentidas por quem a possui, ou seja, um conjunto de convicções obtidas através dos pais, especialmente na infância e mantidas pela sociedade. Stoller estabeleceu uma relação direta entre identidade de gênero e identidade sexual a partir daquilo que ele denominou de núcleo da identidade de gênero, ou seja:

- Uma força originária entre os cromossomos masculinos e femininos (identidade biológica);

Uma designação do sexo do bebê, que, por sua vez, é resultante da observação dos genitais externos deste (identidade anatômica);

- Uma influência de atitudes dos pais e amigos e a interpretação dessas percepções por parte do bebê (processos de socialização);

- Fenômenos biopsíquicos precoces (efeitos pós-natais), causados por padrões habituais de manejo com o bebê; 
E, por último, o desenvolvimento do ego corporal, ou seja, qualidades e quantidades de sensações pelas quais o indivíduo passa (processo de identificação - uma das propriedades do complexo edipiano).

Masculinidade e feminilidade, assim, são encontrados em todas as pessoas, mas em formas e graus diferentes. Ela começa com a percepção de que se pertence a um sexo e não a outro, onde o núcleo da identidade de gênero dá a convicção de que a atribuição do seu sexo foi correta.

"O que o gênero é e o que homens e mulheres são e o tipo de relação que ocorre entre eles são produtos de processos sociais e culturais" (Almeida, 1995, p. 128), porém, "os estereótipos de macho e fêmea, masculino e feminino estão vinculados a uma crescente histeria, onde a sociedade se encontra numa busca por uma nova noção de gênero, não sabendo mais por onde começar" (Spencer, 1996, p. 386).

Diferentemente de Stoller, Robert Connel vai situar a dinâmica das estruturas de gênero através de um modelo de ordenação provisório que vai das relações de poder, passando pelas relações de produção até aquilo que ele denominou de catexias.

Garcia (1998) expõe esses modelos da seguinte forma:

"Relações de poder (subordinação feminina e dominação masculina ${ }^{2}$ ) constituem a principal linha divisória de poder na ordenação dos gêneros nas sociedades ocidentais. Tal estrutura persiste apesar das resistências articuladas, principalmente pelo feminismo, e das mudanças de posição que têm ocorrido na prática, como, por exemplo, o número crescente de mulheres chefes de família.

- Nas relações de produção, a ordenação de gênero se dá no trabalho e na alocação de tarefas. Considera a acumulação capitalista como necessariamente um processo de acumulação ordenado por gênero.

- Catexis (ou catexia, ou ainda, investimento libidinal) é definida nos termos freudianos como energia emocional vinculada a um objeto com gênero definido. As relações que se estabelecem entre o objeto desejante e o objeto do desejo podem ser consensuais ou coercitivas, independentemente de o prazer obtido ser igualmente dado e recebido. Segundo Connel, os desejos sexuais e as práticas sexuais que dão forma a esses desejos e os realizam são aspectos da ordenação de gênero"(Garcia, 1998, p. 44).

Ou seja, para Robert Connel, o gênero é visto "como uma forma de estruturação das práticas sociais em geral, sendo sua ordenação necessariamente vinculada a outras estruturas sociais, tais como raça, etnia, nacionalidade e posição na ordem mundial" (Garcia, 1998, p. 44).

Assim, o que vai definir minha identidade de gênero e sexual? As regras e convenções sociais e/ou culturais definidas pela sociedade, as relações de poder e de produção no trabalho, os jogos identificatórios e as relações que mantiver com pessoas de sexo oposto, de ambos os sexos, ou do mesmo sexo que o meu ou meus caracteres anatômicos?

A anatomia divide os seres humanos em dois tipos físicos distintos quanto à sua genitalidade e ao seu corpo, estabelecendo no meio sociocultural, inclusive, qual a imagem de homem e mulher que se deve tomar como realidade única possível. A anatomia, portanto, o corpo, vai ser tomado como parte da constituição da identidade sexual e de gênero do sujeito, mas "é preciso analisar as idéias que uma sociedade cria acerca do corpo e os discursos que sustentam não somente acerca do corpo dos homens e das mulheres, como também o discurso sobre a sexualidade e um discurso da sexualidade" (Almeida, 1995, p. 138).
As relações que se estabelecem entre o objeto desejante e o objeto do desejo podem ser consensuais ou coercitivas, independentemente de o prazer obtido ser igualmente dado e recebido.
2 sugerimos ao leitor uma aproximação teórica do conceito formulada por Bourdieu (1998). 
No caso do homem, a norma social construída é clara: o homem deve comportar-se como o modelo histórico e social definido pela maioria e enquadrar-se nele, dirigindo sua sexualidade para o sexo oposto ao seu. Ora, "nenhuma identidade sexual é automática, autêntica, facilmente assumida, e existe sem negociação ou construção; toda a identidade sexual é um construto estável, mutável e volátil. Não existe uma identidade heterossexual lá fora, pronta, acabada, esperando para ser assumida, e, de outra, uma identidade homossexual instável" (Louro, 1997, p. 27).

Ao compreender-se que as identidades não são fixas e ao manter a noção de uma identidade sexual ou de gênero, o modelo padrão e normativo passa não só a ser seguido como também cobrado e recomendado sem piedade pela nossa sociedade. Para Margareth Arilha (1998), Robert Connell foi o "responsável por introduzir a idéia da inexistência de uma forma única na construção do masculino nas sociedades, defendendo a idéia de que as masculinidades deveriam ser compreendidas como configurações de prática em torno da posição dos homens nas relações de gênero". Ele fez mais, prossegue a autora, ele "esclarece o uso da expressão 'configuração de prática' como sendo a ênfase nas experiências concretas presentes no cotidiano de muitos homens e não apenas os comportamentos que as sociedades esperam dos homens nos diferentes contextos socioculturais" (p. 51). Porém, precisamos ainda verificar, na História, como a construção dessas diferentes formas de masculinidades se deram para melhor compreendermos essas diversas práticas de se viver às identidades de gênero e sexual, visto que, segundo Almeida (1995), "a distinção entre sexo e gênero é o ponto de partida fundamental para investigar a masculinidade. Baseada na distinção que a Antropologia sempre promoveu entre Biologia e cultura, e elaborada a partir dos anos 60 pela teoria crítica feminista, a separação conceitual entre sexo e gênero dá a entender que o segundo é a elaboração cultural do primeiro. A variação cultural dos papéis femininos e masculinos, bem como dos traços de personalidade, - tipos tidos como normais para cada sexo em cada cultura- (...) trazia o determinismo cultural para o campo da sexualidade" (p. 28).

Vejamos brevemente como a história da sexualidade contribuiu para o fomento da construção da diferença entre os sexos no tocante à questão do gênero.

\section{Algumas considerações acerca da história de masculinidade}

O marco histórico a que nos referimos se inscreve primeiramente nas normas de diferenciação sexual entre homens e mulheres e na concepção dominante do monismo sexual no século XVIII.

No "one-sex-model", que dominou o pensamento anatômico por dois milênios, a mulher era entendida como um homem invertido, cuja vagina era vista como "um pênis interno, os lábios como o prepúcio, o útero como o escroto e os ovários como os testículos" (Laqueur, 2001, p. 16).

Nessa concepção, calcada nos pressupostos de Galeno desde o século III a.C. até o início do século XIX, os ovários sequer tinham um nome específico; era a linguagem que marcava e demarcava a visão da diferenciação sexual. Nesse período, o modelo de perfeição humana estava representado na anatomia masculina, onde a regra fálica distinguia o domínio de superioridade do homem e inferioridade da mulher, a qual era concebida como um homem invertido e inferior, um sujeito menos desenvolvido na escala de perfeição metafísica. Foi apenas com o two-sex-model que sensíveis mudanças passariam a ocorrer. "Primeiro veio a reprodução das desigualdades sociais e políticas entre homens e mulheres, justificada pela norma natural do sexo. Em 
seguida, o que era efeito tornou-se causa. A diferença dos sexos passou a fundar a diferença de gênero masculino e feminino que, de fato, historicamente a antecedera. O sexo autonomizou-se e ganhou o estatuto de fato originário. Revolucionários, burgueses, filósofos, moralistas, socialistas, sufragistas e feministas estavam de acordo em especificar as qualidades morais, intelectuais e sociais dos humanos, partindo-se da diferença sexual entre homens e mulheres" (Costa, 1995a, p. 128).

De acordo com Laqueur (2001), uma anatomia e fisiologia da incomensurabilidade substituiu uma metafísica da hierarquia na representação da imagem da mulher em relação ao homem. Assim, de homem invertido, a mulher passa, então, a ser o inverso do homem e em seu lugar, entraria o que hoje denominamos homossexuais, estabelecendo, assim, o início do estado de decadência masculina, momento este em que se sucederá a primeira crise e o culto à masculinidade (Showalter, 1996; Gay, 1995).

Sob a ameaça de serem associados à figura da mulher, dado os "invertidos sexuais", os homens vitorianos recrudescerão mais do que nunca a sua masculinidade, tanto no aspecto físico como psicológico, construindo para si uma série de papéis e traços representativos da condição masculina. Ser homem, no século XIX, significava, então, não ser mulher, e sob hipótese alguma ser homossexual.

Desse modo, passou-se a valorizar desde o vigor físico, a destreza, a coragem, a capacidade de raciocínio, até os modos de se vestir, andar, falar, a capacidade de conquistar mulheres. Até mesmo a beleza masculina passou a ser valorizada, conforme mostra Peter Gay (1995).

Exemplos de personagens másculos ecoavam através da produção artística vitoriana, representada, sobretudo, na literatura, pintura e escultura da época. Nos círculos de amizade, ressaltavam-se com eloqüência quem representava o mais perfeito ideal de beleza masculina, bem como o ideal de virilidade.
Segundo Badinter (1993), "se a masculinidade se ensina e se constrói, não há dúvida de que ela pode mudar. No século XVIII, um homem digno desse nome podia chorar em público e ter vertigens; no final do século XIX, não o pode mais, sob pena de comprometer sua dignidade masculina. O que se construiu pode, portanto, ser demolido para ser novamente construído" (p. 29).

Esses ideais masculinistas se sustentaram, bem ou mal, até os dias atuais, e mantiveram uma relação de poder sobre as mulheres até o início da década de 60.

O movimento feminista, juntamente aos estudos de gênero, veio criticar a base secular de estrutura de poder que se mantinha até então, nascendo daí os men's studies. Numa divergência de idéias que não conseguem se manter diante de melhor descrição que solucione o mal-estar, a crise da identidade masculina contemporânea será um reflexo "do incremento da participação das mulheres no mundo do trabalho, da maior partilha de responsabilidade e poder entre os sexos, da reconsideração feminista dos papéis tradicionais atribuídos aos homens e às mulheres, da prática do celibato e do desmantelamento dos casais e da família, além da reprodução artificial e do pânico das doenças sexualmente transmissíveis, como a aids" (Dorais, 1994a, p. 14).

A produção literária que se seguiu, a partir dos estudos e pesquisas fomentados pelos men's studies, passaria a propor soluções para sair dessa crise; vejamos, de modo geral, como isso se deu.

\section{A (des)construção da masculinidade: a crítica neopragmática}

Quais eram os modelos tradicionais de masculinidade que os estudos de gênero passaram, então, a criticar? Segundo a literatura 
masculinista, a definição do que era ser homem encerrava-se numa polaridade negativa (não poder chorar, não demonstrar seus sentimentos, não ser mulher ou homossexual, não amar as mulheres como as mulheres amam os homens, não ser um fraco, covarde, perdedor e passivo nas relações sexuais, etc.) e afirmativa (ser forte, corajoso, pai, heterossexual, macho, viril, provedor da família, dominador, destemido, determinado, autoconfiante, independente, agressivo, líder, etc.) na constituição dos traços e papéis sociais. As possibilidades descritivas encerravam-se também numa relação de "ter" (força, dinheiro, músculos, um corpo definido, um pênis, um cromossomo $Y$, um lar, um filho homem, controle das emoções, emprego fixo e tantas mulheres quanto fosse possível durante sua vida sexual ativa) e "poder executar tarefas", tais como "fazer um filho", "manter relações sexuais com várias mulheres", "sair de situações difíceis", "servir à pátria", "sustentar a família", entre outros, ou seja, querendo ou não, os ideais tradicionais de masculinidade vão se reportar sempre ao dado anátomo-fisiológico, bem como aos aspectos psicológicos que hierarquicamente estabeleceram e mantiveram o domínio dos homens sobre as mulheres.

Após o advento do movimento feminista, o modelo tradicional de masculinidade não conseguia se sustentar mais frente às mudanças ocorridas no campo do trabalho, das relações afetivas, sociais e sexuais. Nos países mais desenvolvidos, a celeuma provocada pelo movimento feminista provocou uma outra ainda maior, desta vez por parte dos estudos masculinistas em defesa de melhor definição da identidade do homem contemporâneo, conformando, assim, a atual crise da masculinidade.

Uma das principais críticas que se pode fazer ao novo modelo de masculinidade fomentado pela literatura masculinista está na redefinição do papel de pai do homem contemporâneo.
Segundo a revisão da literatura a que procedemos, a maioria dos autores apontam o fato de que, com o desenvolvimento do movimento feminista, houve uma preocupação com a definição do papel de homem-pai, visto que este tem-se moldado à nova conjuntura política, social e econômica do mundo atual, além da entrada maciça das mulheres no mercado de trabalho e na vida pública. Na busca por essa (re)definição, "estudos sobre paternidade aparecem como no campo particular de ações e investigações. A participação mais efetiva dos homens no cotidiano familiar, particularmente no cuidado com as crianças, aparece sob a égide da expressão "nova paternidade" (Arilha, Ridente e Medrado, 1998, p. 20).

Ora, a "nova paternidade", conforme também descreve Medrado (1998), tem transformado o amor paterno em uma espécie de "mito", tanto quanto o foi o "mito do amor materno", criticado por Badinter (1985). Precisamos melhor verificar que tipo de mito é esse que estamos criando, dado que nem todos os pais e grupos familiares têm-se conformado dentro desses padrões da nova paternidade e da nova família contemporânea. A própria estrutura familiar também tem mudado nas últimas décadas, e hoje já podemos seguramente afirmar, apesar de alguns questionamentos jurídicos e religiosos, que a família, o papel de pai e de mãe têm-se reconfigurado na sociedade atual, constituindo-se inclusive de pais e mães solteiras, divorciadas, e de casais homoeróticos masculinos e femininos.

Baseado nos estudos de gênero, os men's studies e a literatura masculinista tentarão propor soluções para esse mal-estar, como, por exemplo, um modelo de masculinidade mais próximo ao de feminilidade.

\section{Basicamente o quê da feminilidade?}

O modelo de masculinidade para o novo homem estaria baseado na capacidade e 
possibilidade desse homem demonstrar seus sentimentos, de poder amar e se emocionar publicamente sem constrangimento, além de sensibilidade ao invés de agressividade, junto à capacidade de executar tarefas domésticas, maior participação na educação dos filhos, exercício de profissões antes consideradas femininas, admitindo inclusive ganhar menos do que sua companheira. No campo da sexualidade, a possibilidade de falhas no intercurso sexual seria compreensível, e, ao invés de dominador, o homem já admitia ser dominado, ao invés de ativo, ser passivo. Identidades sexuais alternativas, como a homossexual, a bissexual e a transexual, fariam parte das subjetividades masculinas contemporâneas. Finalmente, o machismo estaria deposto e as relações entre homens e mulheres tenderiam a melhorar.

Mas até mesmo a sociedade de consumo se propôs a fomentar o debate. O termo "metrossexual", criado e usado desmedidamente para dar conta desse "novo homem" mais preocupado com a saúde, a beleza estética e o modo de cuidar do seu corpo e das roupas que veste, fez nascer a idéia de que todo homem poderia ter uma preocupação estética consigo, tal como fazem as mulheres, sem, no entanto, perder um grau sequer da sua "masculinidade", ou seja, sem colocar em risco a sua identidade e muito menos a sua preferência sexual.

Mas, se assim o fosse, porque a necessidade de recuperar a masculinidade por parte de alguns homens? Ou por que a necessidade de se buscar, em grupos psicoterápicos, um novo modelo de ser homem? É justamente aí que se insere nossa crítica à literatura masculinista e à identidade de gênero.

A tentativa de redescrição a partir do viés da identidade sexual e de gênero não consegue dar conta da maioria das singularidades de todos os homens, pois necessariamente nem todos conseguem se ver totalmente no modelo tradicional, nem totalmente no modelo que chamaríamos contemporâneo de masculinidade.

Também não vemos sentido, econômica e lingüisticamente falando, em resumir nossa identidade a uma qualidade inerente ao nosso gênero (condição cultural e social de ser masculino/homem, ou feminino/mulher), ou ainda à nossa identidade sexual (condição imprescindível de se afirmar como heterossexual, homossexual, bissexual, ou tantas outras identidades sexuais que a História possa criar).

No que compete ao "novo homem", sujeito da cultura do consumo e da imagem, a figura do "metrossexual" é o personagem central de uma sociedade calcada tiranicamente no consumo, que procura criar uma cultura cada vez mais voltada para os produtos cosméticos, estéticos, para o mundo da moda e para o culto à imagem do corpo, ou ainda, dito de outro modo, o "metrossexual" nada mais pode ser do que um produto fetiche que serve às demandas e necessidades do mercado da imagem e do consumo, encerrando o "novo homem" em mais uma identidade, na qual ele não teria condições de assumir as conseqüências de uma sociedade herdeira do capitalismo tardio e das "tecnologias do self" (Villaça e Góes, 1998).

Ora, se requeremos uma pluralidade identitária, queremos dizer com isso que não podemos resumir a definição do nosso "Eu" a um fechamento identitário da ordem do gênero, pura e simplesmente. Portanto, daí a criar predicados femininos para definir o "novo homem" ou dizer que se necessita de uma nova definição de si durante esta última década para acreditar que ser homem, deve-se enquadrar em algum dos modelos de masculinidades criados, é, ao nosso ver, uma das formas contemporâneas de alienação, para utilizar uma expressão de Maria Rita Kehl (1996).
Ora, se requeremos uma pluralidade identitária, queremos dizer com isso que não podemos resumir a definição do nosso Eu a um fechamento identitário da ordem do gênero, purae simplesmente. 
Quando passamos a ver só a identidade sexual ou de gênero do sujeito, deixamos de ver o que de essencial o sujeito tem, em detrimento apenas à sua identidade.

Acreditamos que podemos construir uma masculinidade ou uma feminilidade sem hegemonia, sem tantos rigorismos ou fechamentos identitários, e a saída que apontamos parte da definição do sujeito, conforme propõe o pensamento neopragmático.

"O sujeito no pensamento neo-pragmático nada mais pode ser do que um efeito da linguagem, e dizer que o sujeito é um efeito da linguagem é dizer que aprendemos a falar do sujeito sem necessitar de nenhum referente, exceto as palavras ou proposições que o definem, podendo evitar mais facilmente que nossas teorias se tornem fetiches, e que os sujeitos, enquanto realidades lingüísticas, sejam reificados em identidades socioideologicamente construídas" (Costa, 1994, pp. 21-53).

Compreendemos, pois, que não será reconstruindo uma nova identidade masculina que se poderá promover uma mudança no pensamento ocidental contemporâneo do que é ser homem. É preciso que se promova uma desconstrução da já sedimentada identidade masculina, patriarcalista, machista, para que seja possível promover acordos intersubjetivos, e podendo entender o mais longe possível "a referência do nós, e reconhecendo como "um de nós" um número cada vez maior de pessoas" (Ropa, 1994, p. 172).

A identidade de gênero não possibilita uma pluralidade de escolhas identitárias, pois, conforme afirma Calligaris (1997), a não correspondência entre sexo e gênero possibilitaria se viver como mulher em um corpo de homem, e como um homem no corpo de uma mulher.
Visto por esse prisma, Costa (1995b) vai afirmar: “(...) Para o neo-pragmatismo, nenhum procedimento racional consistente pode afirmar a permanência empírica ou conceitual de uma mesma identidade essencial do mundo, do sujeito e da linguagem. Conhecemos contingências, e não necessidades. Buscar a identidade do sujeito ou de valores morais no que é perene é uma tarefa fútil. Nenhuma de nossas crenças vem de uma fonte de sentido prévia à ação humana. A História mostrou que inúmeros candidatos ao papel fundacional não resistiram ao teste do tempo. Ou perderam completamente a plausibilidade intelectual ou retraíram-se e converteram-se em crenças opcionais, de grupo ou pessoas. (...) Podemos tratar certas imagens do mundo e do sujeito como universais. Mas isso quer dizer, simplesmente, que certas formas de vida nos são de tal modo familiares que não conseguimos pensar em descrições alternativas do que consideramos natural e universal. Os universais mudam quando mudam as formas de vida. Por conseguinte, tudo o que podemos fazer é aceitar a tradição ética que herdamos, procurar transformá-la ou abandoná-la por outra tradição" (p. 125).

De que nos serve toda a sorte de classificações que resumimos e definimos a identidades de pessoas (sobretudo em espécies sexuais e de gênero), quando apenas recrudescemos o narcisismo das pequenas diferenças e estabelecemos a sexualidade e o gênero como padrões normativos e possibilidades de descrição do sujeito? "Transformamos nossas identidades sexuais e de gênero em um destino, naquilo que nos aprisiona, num destino para "nós" e num inferno para os outros, para aqueles que ousaram questionar os limites da prisão" (Ropa, 1994, pp. 175-176).

O "narcisismo das pequenas diferenças" foi um termo criado por Freud n'O Mal-Estar na Civilização (1929[1930]), e refere-se às pulsões de agressividade dirigidas às minorias. Ele designa uma idéia de pertencimento e 
exclusão a um determinado grupo ou comunidade, onde o grupo tende a afirmar uma unidade em confronto e oposição a outros grupos, criando-se um mito de superioridade, um fechamento identitário do "nós" diante dos "outros". Aliado a isso, temos a intolerância e a crueldade contra indivíduos, concebidos como estranhos, diferentes, que não se adequam às normas estabelecidas por uma "pretensa maioria". Assim, passamos a discriminar indivíduos a partir de uma particularidade física, genética, identitária, sexual, social, entre tantas outras. Veja-se, por exemplo, o preconceito formado contra minorias tais como os negros, os psicóticos, os judeus, as mulheres, os homossexuais, os pobres, os mendigos, os "sem-teto", os "semterra", e tantos outros personagens reais tidos como excluídos.

Produzir uma nova identidade é tentar encerrar nossas subjetividades em modelos sociais e culturais que não necessariamente correspondem à contingência histórica que vivemos, visto que todo e qualquer papel social muda de acordo com a contingência histórica, e o que hoje é desqualificado pode muito bem vir a ser recomendado amanhã.

Priorizar uma identidade masculina despida de qualquer natureza também não nos parece possível, pois priorizar esta ou aquela maneira de definir o sujeito é fazer com que o cidadão comum, o sujeito típico, sofra duplamente ou por não conseguir alcançar o que lhe é solicitado pela mídia, pela indústria da moda, pela cultura da imagem e pela sociedade de consumo, ou por não se achar qualificado diante do apelo dessa mesma cultura que criou seus modelos sociais e identitários.

Assim sendo, a melhor saída para a crise da masculinidade contemporânea é aquela feita através do ideal de auto-enriquecimento proposto por Rorty $(1994,1997)$, ou seja, não pergunte o que realmente eu sou, qual o meu verdadeiro eu, o que de essencial existe em mim, e sim, como posso redescrever-me de maneira a viver uma vida melhor e mais harmônica.

Nas palavras de Costa (1994), "o indivíduo que se descreve a partir desse ideal esforçase por imaginar como novas descrições podem reorientar, de um modo mais satisfatório, aquilo que vive como insatisfação, mal-estar, angústia, medo, desespero, sofrimento ou simplesmente vontade de expandir a capacidade de ser feliz" (p. 21).

Somos, como afirma Davidson, "uma mera rede de crenças e desejos, e nossas subjetividades, uma decorrência direta do uso de nosso vocabulário e linguagens. Crueldade ou solidariedade para com o próximo, dependem, portanto, da maneira como aprendemos a ser sujeitos, da maneira como aprendemos a descrever os outros e a nós mesmos", ou seja, "quanto mais prevalecer o desejo de objetividade em detrimento do de solidariedade - ou, dito em termos freudianos, o fechamento identitário, em detrimento da possibilidade identificatória -, mais tenderemos a encapsular-nos numa definição mesquinha do nós. Exigiremos dos "outros", dos que não se "adequam", dos que não cabem em nossas estreitas definições, o ônus da comprovação de nossa "verdade" ou "superioridade" através de seu rebaixamento, humilhação ou patologização" (Ropa, 1994, p. 173).

O sujeito, no pensamento neo-pragmático, é portanto, um efeito da linguagem, e como tal, pode encontrar inúmeras formas de se redescrever, ou, como diria Bezerra Jr. (1994), "ser um humano é ser sujeito, e isso significa poder descrever-se a si próprio e a seus semelhantes com um vocabulário que não descreve marcas ou características físicas (...) Para descrever o sujeito, é preciso fazer uso do vocabulário intencional, mental ou psicológico; falar de crenças, desejos, medos, 
expectativas, sonhos, ideais, vergonha, ódio, amor, cinismo, escrúpulos, audácia, etc., coisas que só se constituem e são experimentadas por meio da linguagem, portanto, da interação, da cultura, da História" (p. 148).

Se respeitarmos a nossa liberdade identitária de escolha intersubjetiva, ou seja, de acreditarmos que podemos ser realmente aquilo que queremos ser, talvez seja essa uma saída mais rápida no encontro com as nossas singularidades, construídas e desconstruídas a cada tempo, sem divisão, sem abismos entre o normal e o doentio, entre o certo e o errado, e sem fazer da anormalidade ou patologia parteira dos nossos sofrimentos identitários.

\section{Sergio Gomes da Silva}

Psicólogo clínico, Especialista em Sexualidade Humana pelo Centro de Educação da UFPB, Especialista em Direitos Humanos pelo Departamento de Filosofia do Centro de Ciências Humanas, Letras e Artes da Universidade Federal da Paraíba, mestrando em Saúde Coletiva pelo Instituto de Medicina Social/IMS/UERJ.

Universidade Estadual do Rio de Janeiro, Instituto de Medicina Social, Departamento de Política e Instituições de Saúde, Rua São Francisco Xavier, 524 - 70 Andar -

Bloco D - Rio de Janeiro- RJ - 20559-900.

E-mail: sergiogsilva1@yahoo.com.br 
ALMEIDA, Maria Isabel Mendes. Masculino/Feminino: Tensão Insolúvel. Rio de Janeiro: Rocco, 1996.

ALMEIDA, Miguel Vale de. Senhores de Si: uma Interpretação Antropológica da Masculinidade. Lisboa: Fim de Século, 1995.

ARILHA, Margareth. Homens: entre a "Zoeira" e a "Responsabilidade". In Arilha, Margareth; Ridenti, Unbehaum, Sandra G. e Medrado, Benedito (orgs.). Homens e Masculinidades: outras Palavras. São Paulo: Ed. 34, 1998.

ARILHA, Margareth; RIDENTI, UNBEHAUM, Sandra G. e MEDRADO, Benedito (orgs.). Homens e Masculinidades: outras Palavras. São Paulo: Ed. 34, 1998.

BADINTER, Elisabeth. XY: sobre a Identidade Masculina. Rio de Janeiro: Nova Fronteira, 1993.

BADINTER, Elisabeth. Um amor conquistado: o mito do amor materno. Rio de Janeiro: Nova Fronteira, 1985.

BEZERRA JR., Benilton. Descentramento do Sujeito: Reflexão sobre um Implícito pouco Pensado. In Costa, Jurandir Freire (org.). Redescrições de Psicanálise: Ensaios Pragmáticos. Rio de Janeiro: Relume-Dumará, 1994.

BOURDIEU Pierre Conferência do Prêmio Goffman: a Dominacão Masculina Revisitada. In Lins, Daniel (org.). A Dominação Masculina Revisitada. Campinas/SP: Papirus, 1998

CALLIGARIS, Contardo. Sexo. In Jornal Folha de São Paulo, Caderno Mais!, 13 de abril de 1997, p. 05.

CECCARELLI, Paulo Roberto. A Construção da Masculinidade. In Percurso: Revista de Psicanálise, ano X, no 19, 2을 semestre de 1997, pp. 49-56.

COSTA, Jurandir Freire. Psicanálise e Contexto Cultural: Imaginário Psicanalítico, Grupos e Psicoterapias. Rio de Janeiro: Campus, 1989

A Inocência e o Vício: Estudos sobre o Homoerotismo. Rio de Janeiro: Relume-Dumará, 1992.

(org.) Redescrições da Psicanálise: Ensaios Pragmáticos. Rio de Janeiro: Relume-Dumará, 1994.

A Face e o Verso: Estudos sobre o Homoerotismo II São Paulo: Escuta, 1995a.

O Sujeito em Foucault: Estética da Existência ou Experimento Moral. In Tempo Social - Revista de Sociologia da USP, no 7, vol. 1-2, outubro de 1995, 1995b, pp. 121-138.

DORAIS, Michel. O Homem Desamparado. São Paulo: Loyola, $1994 a$.

O Erotismo Masculino. São Paulo: Loyola, 1994b FALCONET, Georges \& LEFAUCHER, Nadine. A Fabricação dos Machos. Rio de Janeiro: Zahar Editores, 1997.

FIGUEIREDO, Luís Cláudio. Questões Ontológicas (e Préontológicas) na Pesquisa dos Processos de Singularização. Trabalho apresentado no Simpósio Internacional "Novos Territórios e Novas Subjetividades", Mestrado de Psicologia Social, UFRS Simpósio Internacional "Mal-Estar e Subjetividade", Mestrado em Psicologia da UNIFOR, março de 1998 (mimeo),1998a.

O Sintoma Social no Brasil: Mal-Estar e Subjetividade Brasileira. Trabalho apresentado no Simpósio Internacional "Novos Territórios e Novas Subjetividades", Mestrado de Psicologia Social, UFRS - Simpósio Internacional "Mal-Estar e Subjetividade"; Mestrado em Psicologia da UNIFOR, março de 1998 (mimeo), 1998b.

FRANCHETTO, Bruna; CAVALCANTI, Maria Laura V. C.; REILBORN, Maria Luíza. Antropologia e Feminismo, In Perspectivas Antropológicas da Mulher. Rio de Janeiro: Zahar Editores, 1980, pp. $11-47$
FREUD, Sigmund. O Mal-Estar na Civilização. Rio de Janeiro: Imago. Ed. Standard Brasileira, Obras Completas, vol. XXI, (1929 [1930]), pp. 75-171.

GARCIA, Sandra Maria.Conhecer os Homens a Partir do Gênero e para além do Gênero. In Arilha, Margareth; Ridenti, Unbehaum, Sandra G., e Medrado, Benedito (orgs.). Homens e Masculinidades: outras Palavras. São Paulo: Ed. 34, 1998.

GAY, Peter. O Cultivo do Ódio: a Experiência da Burguesia da Rainha Vitória a Freud. São Paulo: Cia das Letras, 1995.

HITE, Shere. O Relatório Hite sobre a Sexualidade Masculina. São Paulo: Difel - Difusão Editorial AS, 1982.

KEHL, Maria Rita. A Mínima Diferença: Masculino e Feminino na Cultura. Rio de Janeiro: Imago, 1996.

LAQUEUR, Thomas. Inventando o Sexo: Corpo e Gênero dos Gregos a Freud. Rio de Janeiro: Relume-Dumará, 2001.

LOURO, Guacira Lopes. Gênero, Sexualidade e Educação: uma Perspectiva Pós-estruturalista. Petrópolis: Vozes, 1997.

MEDRADO, Benedito. Homens na Arena do Cuidado Infantil: Imagens Veiculadas pela Mídia. In Arilha, Margareth; Ridenti, Unbehaum Sandra G. e Medrado, Benedito (orgs.). Homens e Masculinidades: outras Palavras. São Paulo: Ed. 34, 1998.

MELLO, Susana Carvalho C. L. Discutindo Verdades: Contribuiçõe do Neo-pragmatismo de Richard Rorty. In Caderno de Metodologia, v. 2, no 2. Rio de Janeiro - PUC-RJ, Centro de Tecnologia e Ciências Humanas, Depto. de Psicologia, 1995, pp. 21-33.

NOLASCO, Sócrates. Masculinidade: Reflexões Contemporâneas. In Reflexões Líricas, no 05, ano 87, v. 87, set.-out., 1993, pp. 71-80. Rocco, 1995

(org.). A Desconstrução do Masculino. Rio de Janeiro:

.O Mito da Masculinidade. Rio de Janeiro: Rocco, 1995b. ROLNICK, Suely \& GUATTARI, Félix. Micropolítica: Cartografias do Desejo. Petrópolis: Vozes, 1996

ROPA, Daniela. "Ela É...o que Você Quiser". In Costa, Jurandir Freire (org.).Redescrições da Psicanálise: Ensaios Pragmáticos. Rio de Janeiro: Relume-Dumará, 1994.

RORTY, Richard. Contingência, Ironia e Solidariedade. Lisboa: Editorial Presença,1994.

Objetivismo, Relativismo e Verdade: Escritos Filosóficos I. Rio de Janeiro: Relume-Dumará, 1997.

SHOWALTER, Elaine. Anarquia Sexual: Sexo e Cultura no Fin de Siècle. Rio de Janeiro: Rocco, 1993.

SILVA, Sergio Gomes da. O Conflito Identitário: Sexo e Gênero na Constituição das Identidades. In Revista Brasileira de Sexualidade Humana, vol. 10, no 01, janeiro/junho. São Paulo: Iglu Editora, 1999, pp. 70-85.

SPENCER, Collin. Homossexualidade: uma História. Rio de Janeiro: Record, 1996.

STOLLER, Robert. Masculinidade e Feminilidade: Apresentações de Gênero. Porto Alegre: Artes Médicas, 1993

VELOSO, Marcelo Augusto. Seja homem! In Caderno do CENAP Tecendo Idéias, no 02. Recife-Pe, nov. de 1996, pp. 09-22.

VILLAÇA, Nízia e GÓES, Fred. Em Nome do Corpo. Rio de Janeiro: Rocco, 1998.

\section{Referências}

